\title{
Glutathione S-Transferase T1 and M1 Gene Polymorphisms among Breast Cancer Susceptible Ghanaians
}

\begin{abstract}
Background: Glutathione S-transferase (GST) gene polymorphism has been associated with breast cancer; however, there are conflicting results. Little or no information exists in the Ghanaian population.
\end{abstract}

Aim: To determine the association between GST polymorphic genes (GSTM1 and GSTT1) and susceptibility to breast cancer in Ghanaian population.

Method: 112 whole blood samples were retrieved from $-80^{\circ} \mathrm{C}$ freezer. Samples comprised 56 female breast cancer patients. Demographic and clinical data were retrieved from records. Patients were age matched with 56 controls. Genomic DNA was extracted; GSTTI and GSTM1 genes amplified using multiplex PCR with appropriate primers and the resultant amplicons separated by agarose gel electrophoresis.

Results: The prevalence of GSTT1 null in patients was $42.9 \%$ and with greater association with breast cancer $(\mathrm{OR}=2.84,95 \% \mathrm{Cl}=1.52-5.29, \mathrm{p}=0.001)$. The heterozygous GSTT1 null/GSTM1 genotype was strongly associated with breast cancer $(\mathrm{OR}=3.02,95 \% \mathrm{Cl}=1.61-5.66, \mathrm{p}<0.001)$. Intriguingly, double deletion of the genes was weakly associated with breast cancer $(\mathrm{OR}=1.21$, $95 \% \mathrm{Cl}=0.51-2.84, \mathrm{p}>0.05)$. However, the presence of both genes was not a risk factor of breast cancer in the patients $(\mathrm{OR}=0.53,95 \% \mathrm{Cl}=0.28-1.09, \mathrm{p}=0.030)$.

Conclusion: The GSTT1 null and GSTT1 null / GSTM1 genotypes may be potential risk factors for breast cancer susceptibility.

Keywords: Breast cancer - glutathione S-transferase - polymorphism - genotypes GSTT1 nullfied Introducer method

Submitted: 26 August 2017; Accepted: 15 September 2017; Published online: 22 September 2017

\section{Introduction}

Cancer has increasingly become a major public health problem in developing countries, including Africa [1]. As public and professional awareness of the cancer problem has grown, so has interest in the pattern of disease presentation, its epidemiology, treatment outcome and pathogenesis [2,3]. By the year 2012, 1.67 million women had been diagnosed with breast cancer globally $[4,5]$. Out of this, there were 133,000 new cases and 63,000 deaths in Africa alone, with increasing incidence of breast and other cancers [3]. To date, however, there has been limited research about breast cancer in Africa.
Emmanuel Ayitey Tagoe*, Benjamin Arko-Boham, Bernice Adjorogbe, Nii Ayite Aryee, Samuel M Adadey, Osborne Quaye, Joe-Nat Clegg-Lamptey Medical Laboratory Sciences, University of Ghana College of Health Sciences, Ghana

*Author for correspondence: eatagoe@yahoo.com 
Breast cancer is the most common and leading cause of cancer related-deaths among women worldwide [6]. In the Sub-Saharan Africa, an incidence rate of 26.2 per 100, 000 was reported with a steady rise [7]. The pattern is not different in Ghana where reported cases increased by $2.6 \%$ between 1996 and 2000 [8,9]. The underlying causes of breast cancer are not immediately known. However, risk factors have been known to include environmental factors such as dietary fat intake and oxidative stress, genetic abnormalities resulting in altered biological functions and family history $[10,11]$. Several studies have shown a strong association between oxidative stress and breast cancer development and the association has been attributed to either reduced levels of circulatory antioxidants or ineffective antioxidant enzymes. Reactive species damage biomolecules including fatty acids, proteins and DNA leading to mutations, a precursor of carcinogenesis $[12,13]$. This suggests that detoxification of reactive agents is an inevitable biological event that may reduce the risk of breast cancer development.

Breast carcinogenesis is still poorly understood. A suggested possible contributing factor to the development of the disease has been the synergistic effect of the cooperation between low-penetrance susceptibility genes and environmental factors [14] with several common low-penetrant genes identified as potential breast cancer susceptibility genes. Of these genes, glutathione S-transferase (GST), which is a principal player in detoxification pathways has been propelled into the limelight $[15,16]$. Glutathione S-transferases (GSTs) are a superfamily of phase II drugmetabolism enzymes that play an important role in detoxifying many carcinogens and reactive metabolite intermediates which potentially damage cells and lead to cancers including that of the breast $[17,18]$. GSTs, which are induced under conditions of oxidative stress including increased environmental carcinogenic perturbations [19], are highly polymorphic and individuals with different GST genotypes are reported to show varying responses to environmental toxins or their metabolic intermediates [20].

Human cytosolic GSTs are classified into eight distinct classes and some variants have been linked with accumulation of carcinogens [21]. GST isoforms GSTM1, GSTT1 and GSTP1 are present in both normal and breast tumor tissues and belong to the best characterized classes. GSTT1 and GSTM1 genotypes are of great interest and important because they possess present/null polymorphism. The null genotypes lack the gene products, GSTT1 and GSTM1 enzymes [16,22] and thus a total absence of the respective enzyme activity. The noted GST polymorphism and its association with risk of developing breast cancer has been a focus for research scientists and has drawn growing attention but the results have been varying and inconclusive [23]. GSTM1 gene polymorphism has been associated with point mutation and shows variable distribution among populations $[17,20]$. Research evidence has attempted linking null expression of GSTM1 to deletion of the gene and homozygosity implicated in poor prognosis of cancers [17]. Accumulated evidence has revealed a strong association between complete deletion of GSTT1 gene or amino acids substitution and malfunction of the enzyme in humans [24].

The present study was done with the aim to determine the prevalence of GSTT1 and GSTM1 genes polymorphism in Ghanaian women diagnosed with breast cancer and to investigate the prognostic significance of GST polymorphism in the disease. Currently, scanty information exists on the prevalence of the GST gene variants and their association with breast cancer development in Ghanaians. The study is first to report the prevalence of GSTM1 and GSTT1 null and their association with breast cancer development in Ghanaian patients diagnosed with the disease.

\section{Methods}

\section{Blood Samples}

Archived whole blood samples of clinically diagnosed breast cancer patients and controls were retrieved from $-80^{\circ} \mathrm{C}$ deep freezer. A total of 112 samples from 56 patients and 56 age-matched controls, were included in the study. Breast cancer blood donors had previously been recruited from the Chemotherapy Unit of the Department of Surgery, Korle Bu Teaching Hospital, Accra, Ghana. In recruitment, all patients with other diagnosed malignancies besides breast cancer were excluded. Control group members were apparently healthy non-breast cancer individuals recruited from the immediate environs of the hospital. Blood samples $(5 \mathrm{ml})$ were collected from participants and had been stored at $-80^{\circ} \mathrm{C}$ until use in this study. All study participants gave their consent before enrolment into the study. Study was reviewed and approved by the Protocol and Ethical Review Committee of the School of Biomedical and Allied Health Sciences, University of Ghana.

\section{Blood sample and DNA extraction}

The frozen whole blood samples in EDTA-coated eppendorf tubes were thawed at room temperature 
and genomic DNA extracted from $200 \mu \mathrm{l}$ portion of the blood sample using the QIAamp DNA Mini kit (Qiagen, Inc., USA) following the manufacturer's protocol. A Thermo Fischer Nanodrop Lite was used to check the purity and yield of the DNA obtained.

\section{Multiplex PCR for GSTT1 and GSTM1 genes}

A multiplex PCR assay was performed using reagents and primers from Qiagen, Inc. USA. A $50 \mu \mathrm{l}$ multiplex reaction mixture contained PCR master mix, $2.5 \mu \mathrm{l}$ of each primer and $2.5 \mu \mathrm{l}$ of extracted DNA as template for gene amplification. The GSTM1 primers (forward - 5' GAACTCCCTGAAAAGCTAAAGC 3' and reverse -5' GTTGGGCTCAAATATACGGTGG 3 ') were used for the amplification of the 215bp fragment. The primers for GSTT1 (forward - 5' TTCCTTACTGGTCCTCACATCTC 3' and reverse - 5' TCACCGGATCATGGCCAGCA 3') were for amplification of the $480 \mathrm{bp}$ fragment. Also, primers (forward - 5' GAACTGCCACTTCAGCTGTCT 3' and reverse- 5' CAGCTGCATTTGGAAGTGCTC 3') were added to amplify the exon 7 of the CYP1A1 gene as an internal control. The cycling conditions involved an initial pre-treatment temperature of $94^{\circ} \mathrm{C}$ for 5 minutes followed by 35 cycles of PCR amplification. Amplification conditions employed were: DNA strand denaturation at $94^{\circ} \mathrm{C}$ for 2 minutes, primer annealing at $59^{\circ} \mathrm{C}$ for 1 minute and extension at $72^{\circ} \mathrm{C}$ for 1 minute. A final extension step at $72^{\circ} \mathrm{C}$ for 10 minutes ended the process.

\section{Detection of GSTT1 and GSTM1 genes}

The amplicons were separated on $2 \%$ agarose gel and stained with ethidium bromide. Bands were visualized under UV light and the presence of the GSTT1, GSTM1 and CPY1A1 bands were detected by the presence of band 480, 315 and 215bp on the gel. The participants were grouped as either positive or null genotypes.

\section{Results}

\section{Clinical presentations of patients and controls}

A total of 112 whole blood samples were included in the study of which there were 56 each for breast cancer patients and apparently healthy controls. Clinical data including BMI and blood pressure were also retrieved from patients' hospital records. Participants were all females with mean ages 49.77 and 48.25 years for breast cancer patients and controls, respectively. The body mass index (BMI) and blood pressure of patients as shown in Table 1 were significantly higher $(p<0.05)$ than those of the control group. The mean
BMI of $30.37 \pm 6.51 \mathrm{~kg} / \mathrm{m}^{2}$ for the breast cancer patients suggests that most of them were obese.

\section{Distribution of glutathione S-transferase genes among the study population}

Figure 1 is a representative gel showing the separation of GSTT1 and GSTM1 gene amplicons on agarose gel. The combined genes and individual genes presentation of glutathione S-transferase is shown in Table 2. Breast cancer patients showed significantly lower percentage of GSTT1+/GSTM1+ than the apparently healthy controls $(\mathrm{p}<0.05)$. The GSTT1-/GSTM1+ combined gene was highly presented in the patients than controls $(\mathrm{p}<0.05)$ and may be the contribution from the individual gene GSTT1- (27.5\%). Though not statistically significant, double deletion of the genes in the patients was higher than the controls. Among the patients, 37.5\% was GSTM1 positive as against 33.9\% of the controls (Table 2).

\section{Association between GST gene polymorphism and breast cancer development}

The combined GST genotypes of breast cancer patients compared with controls are shown in Table 3. The GSTT1- and GSTT1-/GSTM1+ were over-

\begin{tabular}{|c|c|c|c|}
\hline Parameter & $\begin{array}{c}\text { Breast Cancer } \\
\text { Patients } \\
(\mathrm{N}=56)\end{array}$ & $\begin{array}{c}\text { Controls } \\
(\mathrm{N}=56)\end{array}$ & p-value \\
\hline Age (years) & $49.77 \pm 10.32$ & $48.25 \pm 11.24$ & 0.457 \\
\hline BMI $\left(\mathrm{kg} / \mathrm{m}^{2}\right)$ & $30.37 \pm 6.51$ & $23.09 \pm 1.88$ & $<0.0001^{*}$ \\
\hline SBP (mmHg) & $131.55 \pm 18.50$ & $124.61 \pm 9.15$ & $0.013^{*}$ \\
\hline $\mathrm{DBP}(\mathrm{mmHg})$ & $79.64 \pm 11.42$ & $71.52 \pm 5.98$ & $<0.0001^{*}$ \\
\hline
\end{tabular}

N: Number: BMI: Body Mass Index; SBP: Systolic Blood Pressure; DBP: Diastolic Blood Pressure. Values are presented as mean \pm standard deviation. ${ }^{*}$ mean difference is statistically significant. $p \leq 0.05$ is considered significant.

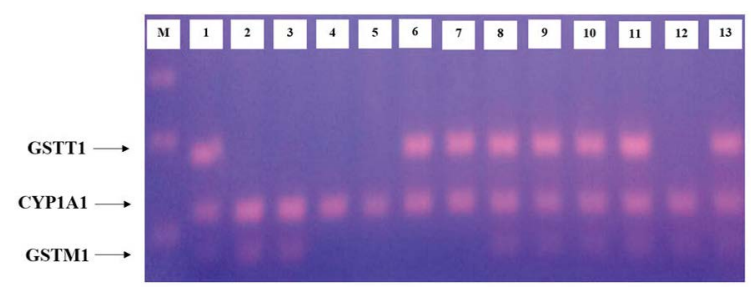

Figure 1. Representative GSTT1 and GSTM1 gene amplicons separated on agarose gel. PCR amplification of GSTM1 (215 bp) and GSTT1 (480 bp) with CYP1A1 (312 bp) gene as an internal control. The amplicons were separated on $2 \%$ agarose/ethidium bromide gel electrophoresis. Molecular ladder (M) of $100 \mathrm{bp}$ was used. Lanes 6 and 7 show only the GSTT1 genes, while 2, 3 and 12 show only GSTM1 genes. The lanes 1, 8, 9,10 11, and 13 show the presence of both genes. The lanes 4 and 5 show double deletion of the genes showing only the internal control and CYP1A1. 
Table 2. Glutathione S-transferase gene polymorphism frequencies in the study population

\begin{tabular}{|c|c|c|c|c|}
\hline Genotypes & $\begin{array}{l}\text { Breast } \\
\text { Cancer } \\
\text { Patients } \\
(\mathrm{N}=\mathbf{5 6})\end{array}$ & $\begin{array}{l}\text { Controls } \\
(\mathrm{N}=56)\end{array}$ & $x^{2}$ & p-value \\
\hline \multicolumn{5}{|c|}{$\begin{array}{l}\text { Combined Genes [n } \\
(\%)]\end{array}$} \\
\hline $\mathrm{GSTT}^{+} / \mathrm{GSTM}^{+}$ & $18(32.1)$ & $27(48.2)$ & 4.69 & $<0.05^{*}$ \\
\hline GSTT1+/GSTM1 ${ }^{-}$ & $7(12.5)$ & $12(21.4)$ & 1.31 & NS \\
\hline GSTT1 $/$ GSTM1+ & $24(42.9)$ & $11(19.7)$ & 10.13 & $<0.005^{*}$ \\
\hline GSTT1 $1 / G S T M 1-$ & $7(12.5)$ & $6(10.7)$ & 0.78 & NS \\
\hline \multicolumn{5}{|c|}{$\begin{array}{l}\text { Individual Genes [n } \\
(\%)]\end{array}$} \\
\hline $\mathrm{GSTT}^{+}{ }^{+}$ & $25(22.3)$ & $39(34.8)$ & 3.53 & NS \\
\hline GSTT1- & $31(27.7)$ & $17(15.2)$ & 4.27 & $<0.05^{*}$ \\
\hline GSTM1+ & $42(37.5)$ & $38(33.9)$ & 0.20 & NS \\
\hline GSTM1- & $14(12.5)$ & $18(16.1)$ & 0.16 & NS \\
\hline
\end{tabular}

GSTT1+/GSTM1+ means both genes were present, GSTT1-/GSTM1means both genes were deleted. NS means difference between proportion is not significant. ${ }^{*} p<0.05$ is considered statistically significant.

Table 3. Association of GST gene polymorphism with breast cancer development

\begin{tabular}{|c|c|c|c|c|}
\hline Subjects & GSTT1 - & $\begin{array}{l}\text { GSTT1+1 } \\
\text { GSTM1 }^{+}\end{array}$ & $\begin{array}{l}\text { GSTT1 }{ }^{\prime} \\
\text { GSTM1+ }^{+}\end{array}$ & $\begin{array}{l}\text { GSTT1 } / \\
\text { GSTM1- }\end{array}$ \\
\hline Odds ratio (OR) & 2.84 & 0.51 & 3.02 & 1.20 \\
\hline $95 \% \mathrm{Cl}$ & $\begin{array}{l}1.52- \\
5.29\end{array}$ & $0.28-1.09$ & $1.61-5.66$ & $0.51-2.84$ \\
\hline$p$-value & $<0.001^{*}$ & $0.030^{*}$ & $<0.001$ & $>0.05$ \\
\hline
\end{tabular}

Combined genes were used for calculation. '-'means genes were not amplified and was considered deleted (null gene). ' + ' means gene was amplified. "OR is statistically significant at $p \leq 0.05$.

presented among the breast cancer patients than controls. Both genotypes were strongly associated with breast cancer development $(\mathrm{p}<0.05)$. Even though not statistically significant, double deletion may increase the risk of developing breast cancer $(\mathrm{OR}=1.2, \mathrm{p}>0.05)$. However, the presence of both genes (GSTT1+l GSTM1+) may reduce the risk of developing breast cancer $(\mathrm{OR}=0.51, \mathrm{p}<0.05)$.

\section{Discussion}

The current study is the first to report association between breast cancer and GSTT1 and GSTM1 genes polymorphism in Ghanaian patients. The motivation for this study was to determine the association between GST polymorphic genes (GSTM1 and GSTT1) and susceptibility to breast cancer in Ghanaian population using an available small sample $(\mathrm{n}=56)$. Glutathione $\mathrm{S}$-transferase gene polymorphism has widely been studied in several disease conditions but conflicting results have been reported [25]. In this study, prevalence of GSTT1 null was higher in breast cancer patients and was strongly associated with the disease. The result however, showed no association between GSTM1 null and breast cancer development. Intriguingly, patients with GSTT1 null/GSTM1 genotype were at higher risk of developing breast cancer compared to other genotypes. Presence of both genotypes may play a protective role against breast cancer development but the frequency was lower in the patients compared with control group. However, double deletion of the genes may increase the risk of developing breast cancer even though association was not statistically significant in this study.

A meta-analysis and case-control studies revealed a strong association between GSTT1 null and breast cancer $[25,26]$. However, no association was reported between breast cancer and GSTM1 null $[27,28]$. These studies support our current findings. Ying-Hao et al. [29] reported that, individuals with GSTT1 null/GSTM1 genotype and those with double deletions have increased risk of developing hepatocellular cancer (HCC). Homozygous deletion of GSTT1 and GSTM1 genes has also been studied and found to increase the risk of developing breast cancer [30]. Also, another study [31] reported high prevalence of double deletion in breast cancer patients but did not associate the deletion with the risk of developing the disease. Despite the reported association of GST genes polymorphism with breast cancer, few studies have presented divergent results [32-34].

The etiology of breast cancer is not precisely known. However, many risk factors have been identified including increased systemic concentration of reactive oxygen species [35]. Free reactive species cause irreversible damage such as point mutations or chromosomal aberration in DNA resulting in tumor initiation. Thus, biological agents that reduce the levels of reactive species may play a vital role in reducing the risk of developing breast cancer [35,36]. Glutathione S-transferases (GSTs) are phase II enzymes and important in clearance of xenobiotic and reactive oxygen species thereby protecting DNA from damage. Glutathione $S$-transferases inactivate cytotoxic and genotoxic compounds within cells and consequently curtailing cytotoxicity and mutagenesis [18]. The double deletion of GST genes and GSTT1 null may be critical for the initiation of DNA damage resulting in carcinogenesis. Double deletion of genes and GSTT1 null were implicated in conditions of increased oxidative stress and may be partly accountable for the resultant cellular damage [37].

In the present study breast cancer patients had increased body mass index (BMI) compared with 
the apparently healthy controls. The association between overweight and obesity and breast cancer is well established [38,39]. Obesity-induced chronic inflammation results from adipocytes dysfunction and has been mentioned to be the underlying cause of breast cancer development in obese women [40]. Chronic inflammation promotes the release of interleukins which are agents of oxidative stress with possible mutagenesis $[41,42]$. Elevated blood pressure reported in breast cancer patients in this study corroborates previous report by Jung and colleagues [43] who argue in support of evidence that links hypertension with survival of patients diagnosed with metastatic breast cancer which may explain survival disparity between younger and older patients. In as much as the sample size used in the study may be relatively small, the findings are interesting and this is the first ever report on the subject on a sub-Saharan African population where breast cancer has a high mortality rate and sets the tone for a large-scale investigation.

\section{Conclusion}

We conclude that GSTT1 null and GSTT1 null/
GSTM1 may be potential risk factors for breast cancer susceptibility in Ghanaian patients, underlying the fact that increased antioxidants may mitigate tumorigenic activities by reducing oxidative stress and controlling DNA damage. However, in the light of the small sample size which is an obvious limitation of this study, we recommend further studies to be conducted with a larger population size to establish the effect of the GST polymorphisms on the advancement of breast cancer in Ghanaians. In addition, the role of increased BMI and blood pressure in the etiology of breast cancer needs further investigations especially in populations of African descents.

\section{Acknowledgements}

We thank Patient Aglago, Joshua Kuleape and the staff of the Virology Laboratory, Department of Biochemistry, Cell and Molecular Biology, WACCBIP, University of Ghana, Legon, Accra for their tremendous support.

\section{Competing Interest}

The authors declare that they have no competing interests.

\section{Executive summary}

Background: Glutathione S-transferase (GST) gene polymorphism has been associated with breast cancer, however, there are conflicting results. Little or no information exists in the Ghanaian population.

Aim: To determine the association between GST polymorphic genes (GSTM1 and GSTT1) and susceptibility to breast cancer in Ghanaian population.

Method: 112 whole blood samples were retrieved from $-80^{\circ} \mathrm{C}$ freezer. Samples comprised 56 female breast cancer patients. Demographic and clinical data were retrieved from records. Patients were age matched with 56 controls. Genomic DNA was extracted GSTTI and GSTM1 genes amplified using multiplex PCR with appropriate primers and the resultant amplicons separated by agarose gel electrophoresis.

Results: The prevalence of GSTT1 null in patients was $42.9 \%$ and with greater association with breast cancer (OR=2.84, $95 \%$ $\mathrm{Cl}=1.52-5.29, \mathrm{p}=0.001)$. The heterozygous GSTT1 null/GSTM1 genotype was strongly associated with breast cancer $(\mathrm{OR}=3.02$, $95 \% \mathrm{Cl}=1.61-5.66, \mathrm{p}<0.001)$. Intriguingly, double deletion of the genes was weakly associated with breast cancer $(\mathrm{OR}=1.21,95 \%$ $\mathrm{Cl}=0.51-2.84, \mathrm{p}>0.05)$. However, the presence of both genes was not a risk factor of breast cancer in the patients $(\mathrm{OR}=0.53,95 \%$ $\mathrm{Cl}=0.28-1.09, \mathrm{p}=0.030$ ).

Conclusion: The GSTT1 null and GSTT1 null / GSTM1 genotypes may be potential risk factors for breast cancer susceptibility.

\section{References}

1. Farmer P, Frenk J, Knaul FM, Shulman LN, Alleyne G, Armstrong L, et al. Expansion of cancer care and control in countries of low and middle income: a call to action. Lancet 376: 1186-1193 (2010).

2. Akarolo-Anthony SN, Temidayo O, Ogundiran TO, Adebamowo CA. Emerging breast cancer epidemic: evidence from Africa. Breast Cancer Research 12: 8 (2010).

3. Ogunbiyi JO, Stefan DC, Rebbeck TR. African Organization for Research and Training in Cancer: position and vision for cancer research on the African Continent. Infect Agent Cancer 11: 63
(2016).

4. Ferlay J, Shin HR, Bray F, Forman D, Mathers C, Parkin DM. GLOBOCAN 2008 v12, cancer Incidence and Mortality Worldwide. IARC Cancer Base No, 10. International Agency for Research on Cancer, Lyon, France (2010).

5. International Agency for Research on Cancer, IARC. World cancer report 2012. Lyon, International Agency for Research on Cancer (2012).

6. Ferlay J, Shin HR, Bray F, Forman D, Mathers C, Parkin DM. Estimates of worldwide burden of cancer in 2008: GLOBOCAN 2008. Int J Cancer 127: 2893-2917 (2010). 
7. Jemal A, Bray F, Forman D, O’Brien MM, Ferlay J, Center M, et al. Cancer Burden in Africa and Opportunities for Prevention. Cancer 118: 4372-4384 (2012).

8. Biritwum RB, Gulaid J, Amaning AO. Pattern of diseases or conditions leading to hospitalisation at the Korle Bu Teaching hosipital. Ghana Med J34: 197-205 (2000).

9. Badoe EA, Baako BN. The Breast. In Badoe EA, E.Q. Archampong, da Rocha-Afodu, Principles and Practice of Surgery including pathology in the tropics. Accra: Department of Surgery, University of Ghana Medical School (2000).

10. Vallon-Christersson J, Cayanan C, Haraldsson K, Loman N, Bergthorsson JT, Brøndum-Nielsen K, et al. Functional analysis of BRCA1 C-terminal missense mutations identified in breast and ovarian cancer families. Hum Mol Genet 10: 353-360 (2001).

11. Noda N, Wakasugi H. Cancer and oxidative stress. Japan Med Assoc J 44: 535-539 (2001).

12. Halliwell B, Gutteridge JC. The definition and measurement of antioxidants in biological systems. Free Radic Biol Med 18: 125126 (1995).

13. Yeon JY, Suh YJ, Kim SW, Baik HW, Sung CJ, Kim HS, et al. Evaluation of dietary factors in relation to the biomarkers of oxidative stress and inflammation in breast cancer risk. Nutrition 27: 912-918 (2011).

14. Lichtenstein P, Holm NV, Verkasalo PK. Environmental and heritable factors in the causation of cancer. $N$ Engl J Med 343: 78-85 (2000).

15. Yager JD, Davidson NE. Estrogen carcinogenesis in breast Cancer. N Engl J Med 354: 270-282 (2006).

16. Chen XX, Zhao RP, Qiu LX, Yuan H, Mao C, Hu XC, et al. Glutathione $\mathrm{S}$-transferase T1 polymorphism is associated with breast cancer susceptibility. Cytokine 56: 477-480 (2011).

17. Sá RA, Moreira AD, Cabello PH, Ornellas AA, Costa EB, Matos $\mathrm{CD}$, et al. Human glutathione $S$-transferase polymorphisms associated with prostate cancer in the Brazilian population. International brazj jurol 40: 463-473 (2014).

18. Hayes JD, Pulford DJ. The glutathione S-transferase supergene family: regulation of GST and the contribution of the isoenzymes to cancer chemoprotection and drug resistance. Crit Rev Biochem Mol Biol 30: 445-600 (1995).

19. Khedhaier A, Remadi S, Corbex M, Ahmed SB, Bouaouina $\mathrm{N}$, Mestiri S, et al. Glutathione S-transferases (GSTT1 and GSTM1) gene deletions in Tunisians: susceptibility and prognostic implications in breast carcinoma. Br J Cancer 89: 1502-1507 (2003).

20. Ebeshi BU, Bolaji OO, Masimirembwa CM. Glutathione$\mathrm{S}$-transferase (M1 and T1) polymorphisms in Nigerian populations. J Med Genet Genom 3: 56-60 (2011).

21. Strange RC, Spiteri MA, Ramachandran S, Fryer AA. Glutathione S-transferase family of enzymes. Mutat Res 482: 21-26 (2001).

22. Pemble S, Schroeder KR, Spencer SR. Human glutathione Stransferase u(GSTT1): cDNA cloning and the characterization of a genetic polymorphism. Biochem J 300: 271-276 (1994).

23. Bansal VK, Rajan K, Sharma A, Paliwal P, Chaubal G, Jindal $\mathrm{V}$, et al. Prospective Case-Control Study to Evaluate the Role of Glutathione S Transferases (GSTT1 and GSTM1) Gene Deletion in Breast Carcinoma and Its Prognostic Significance. Indian J Surg 77: 1067-1072 (2015).
24. Helzlsouer KJ, Selmin O, Huang HY, Strickland PT, Hoffman S, Alberg AJ, et al. Association Between Glutathione S-Transferase M1, P1, and T1 Genetic Polymorphisms and Development of Breast Cancer. J Natl Cancer Inst 90: 512-518 (1998).

25. Fang J, Wang S, Zhang S, Su S, Song Z, Deng Y, et al. Asociation of the Glutathione S-Transferase M1, T1 Polymorphisms with Cancer: Evidence from a Meta-Analysis. PLoS ONE 8: 78707 (2013).

26. Chen X, Zhao RP, Qiu LX, Yuan H, Mao C, Hu XC, et al. Glutathione S-transferase T1 polymorphism is associated with breast cancer susceptibility. Cytokine 56: 477-480 (2011).

27. Saadat I, Omidvari S, Saadat M. Genetic Polymorphism of the Glutathione S-Transferase M1 and Development of Breast Cancer. Iran. Biomed J 5: 21-25 (2001).

28. Zhong S, Wyllie AH, Barnes D, Wolf CR, Spurr NK. Relationship between the GSTM1 genetic polymorphism and susceptibility to bladder, breast and colon cancer. Carcinogenesis 14: 1821-1824 (1993).

29. Shen YH, Chen S, Peng YF, Shi YH, Huang XW, Yang GH, et al. Quantitative assessment of the effect of glutathione S-transferase genes GSTM1 and GSTT1 on hepatocellular carcinoma risk. Tumor Biology 35: 4007-4015 (2014).

30. Possuelo LG, Peraça CF, Eisenhardt MF, Dotto ML, Cappelletti L, Foletto El, et al. Polymorphisms of GSTM1 and GSTT1 genes in breast cancer susceptibility: a case-control study. Rev Bras Ginecol Obstet 35: 569-574 (2013).

31. Khedhaier A, Remadi S, Corbex M, Ahmed SB, Bouaouina $\mathrm{N}$, Mestiri S, et al. Glutathione S-transferases (GSTT1 and GSTM1) gene deletions in Tunisians: susceptibility and prognostic implications in breast carcinoma. Br J Cancer 89: 1502-1507 (2003).

32. Strange RC, Lear JT, Fryer AA. Glutathione S-transferase polymorphisms: influence on susceptibility to cancer. Chem Biol Interact 111: 351-364 (1998).

33. Hashemi M, Eskandari-Nasab E, Fazaeli A, Taheri M, Rezaei $\mathrm{H}$, Mashhadi M, et al. Association between polymorphisms of glutathione S-transferase genes (GSTM1, GSTP1 and GSTT1) and breast cancer risk in a sample Iranian population. Biomark Med 6: 797-803 (2012).

34. Rodríguez M, Mejia F, Lecourtois M, Domínguez V, Castillo J. Influence of GSTT1, GSTM1 and GSTP1 Polymorphisms on the Development of Breast Cancer. J Cancer Ther 5: 552-559 (2014).

35. Sosa V, Moliné T, Somoza R, Paciucci R, Kondoh H, LLeonart ME. Oxidative stress and cancer: an overview. Ageing Res Rev 12: 376-390 (2013).

36. Pan SY, Zhou J, Gibbons L, Morrison H, Wen SW. Antioxidants and breast cancer risk- a population based case-control study in Canada. BMC Cancer 11: 372-384 (2011).

37. Datta SK, Kumar V, Ahmed RS, Tripathi AK, Kalra OP, Banerjee BD. Effect of GSTM1 and GSTT1 double deletions in the development of oxidative stress in diabetic nephropathy patients. Indian J Biochem Biophys 47: 100-103 (2010).

38. Calle E, Rodriguez C, Walker-Thurmond K, Thun M. Overweight, obesity, and mortality from cancer in a prospectively studied cohort of U.S. adults. N Engl J Med 348: 1625-1638 (2003).

39. Hakkak R, Korourian S, Melnyk S. Obesity, Oxidative Stress and Breast Cancer Risk. J Cancer Sci Ther 5: 129 (2013). 
40. Crujeiras AB, Díaz-Lagares A, Carreira MC, Amil M, Casanueva FF. Oxidative stress associated to dysfunctional adipose tissue: a potential link between obesity, type 2 diabetes mellitus and breast cancer. Free Radic Res 47: 243-256 (2013).

41. Wassmann S, Stumpf M, Strehlow K, Schmid A, Schieffer B, Böhm M, et al. Interleukin-6 Induces Oxidative Stress and Endothelial Dysfunction by Overexpression of the Angiotensin II Type 1 Receptor. Circ Res 94:534-541 (2004).
42. Gabay C. Interleukin-6 and chronic inflammation. Arthritis Res Ther 8: 3 (2006).

43. Jung SY, Rosenzweig M, Linkov F, Brufsky A, Joel L, Weissfeld $\mathrm{JL}$, et al. Comorbidity as a Mediator of Survival Disparity Between Younger and Older Women Diagnosed with Metastatic Breast Cancer. Hypertension 59: 205-211 (2012). 